\title{
O DIREITO AGRÁRIO E O DIREITO DE PROPRIEDADE: ASPECTOS DA SERVIDÃO ADMINISTRATIVA EM PROPRIEDADES QUE DESCUMPREM A FUNÇÃO SOCIAL.
}

\section{THE AGRARIAN LAW AND THE LAW PROPERTY: ASPECTS OF EASEMENTS ON PROPERTIES THAT VIOLATE THE SOCIAL FUNCTION.}

${ }^{1}$ Daniel Augusto Ribeiro

\section{RESUMO}

$\mathrm{O}$ direito à propriedade privada está presente no Direito e na realidade brasileira, cujos institutos de proteção são assegurados pela legislação. Nesse sentido, o cumprimento da função social é um dos requisitos que confere proteção à propriedade agrária, estando assegurada no texto constitucional, que também estabelece as exceções para o exercício e autorizam a intervenção do Estado, como a instituição de servidões administrativas. Cabe, no entanto, indenização pelos prejuízos que efetivamente caracterizem a redução do potencial econômico da propriedade, o que conciliado com aspectos públicos e constitucionais, será mitigado caso não se tenha o cumprimento da função social.

Palavras-chave: Propriedade agrária, Função social, Atividade agrária, Servidão administrativa

\begin{abstract}
The right to private property is present on the Right and the Brazilian reality, whose protection institutes are ensured by law. In this sense, the fulfillment of the social function is a prerequisite that provides protection to land ownership, is ensured in the Constitution, which also establishes exceptions to the exercise and allow state intervention, such as the institution of administrative easement. It is, however, compensation for losses that effectively characterize the reduction in the economic potential of the property, which reconciled with public and constitutional aspects, will be mitigated if have no fulfillment with the social function.
\end{abstract}

Keywords: Agrarian property, Social function, Agricultural activity, Easements

1 Mestre em Direito Agrário pela Universidade Federal de Goiás - UFG, Goiás (Brasil). E-mail: danielaugustoribeiro@gmail.com 


\section{INTRODUÇÃO}

O desenvolvimento da humanidade tem sido possível graças à organização social e à existência de insumos como transportes, comunicações, abastecimento alimentar. A produção de alimentos é um dos objetos do Direito Agrário, dele se destacando as atividades agrárias e o direito de propriedade como elementos chaves para conferir segurança jurídica para a produção e circulação das riquezas oriundas do meio agrário.

No que se refere ao direito de propriedade, há circunstâncias em que o Poder Público necessita realizar intervenções, amparado legalmente e em determinadas hipóteses com proteção constitucional. Nesse sentido, tais intervenções podem ocorrer inclusive em propriedades produtivas e que cumprem a função social.

Diante disso, tem-se o seguinte problema jurídico: quais impactos provocados na propriedade agrária resultantes de intervenções estatais, como a servidão administrativa, e quais os mecanismos de mitigação destes efeitos?

Com o objetivo geral de compreender os impactos decorrentes da intervenção estatal na propriedade agraria produtiva, tem-se como objetivos específicos: (a) compreender o direito de propriedade, com ênfase na propriedade agrária, e os institutos de intervenção como a servidão administrativa; (b) investigar os aspectos econômicos e indenizatórios quando da intervenção e possibilidades de mitigar os efeitos resultantes de tais intervenções.

A metodologia de abordagem responsável pelo raciocínio utilizado no desenvolvimento da pesquisa foi o indutivo, partindo dos pontos particulares postos para uma questão mais ampla e geral (generalização). Como técnica metodológica, adotou-se a pesquisa teórica e estudos de caso, mediante coleta e análise de documentos, legislação e jurisprudências.

Para a estrutura da pesquisa, levaram-se em consideração os princípios e interesses sociais aplicáveis tanto ao Direito Agrário. Assim, se dedicará à compreensão do Direito Agrário e dos respectivos institutos jurídicos de proteção da propriedade agrária. A finalidade é compreender quais os elementos distingue essa forma de propriedade e que princípios norteiam a atuação estatal, tanto legislativa, quanto de políticas públicas.

Serão feitas considerações ao Direito de Propriedade, geral e a que se aplica ao imóvel agrário, e sobre os contornos jurídicos do Direito Agrário, em especial sobre dois de seus elementos fundantes: atividade agrária e função social.

Por fim serão verificadas as exceções que autorizam a intervenção estatal na propriedade. Dentre os institutos de estudo, se deterá na servidão administrativa, visto ser a 
forma mais comum quando se tem a implantação de linhas de transmissão de energia elétrica. Portanto, deverá se verificar os elementos e competências para sua instituição e os efeitos decorrentes.

Por fim, serão avaliados os efeitos de intervenção estatal na propriedade agrária, iniciando pelo caráter da indenização de terras produtivas que não cumprem a função social. Serão avaliados também os aspectos ambientais e medidas de mitigação das intervenções, levando em consideração um processo sustentável de desenvolvimento.

\section{INSTITUTOS JURÍdICOS DE PROTEÇÃO DA PROPRIEDADE AGRÁRIA}

Um dos pilares que compõe a organização dos homens em sociedade está o direito de propriedade. Assim, os membros de uma coletividade em que o direito de propriedade vigore com regularidade, podem manejar institutos jurídicos para proteção de seu patrimônio, e segurança para adquirir ou dispor de seus bens, fatores necessários para o desenvolvimento econômico e social.

Por ser um tema caro ao Direito, passa-se a uma compreensão do conceito de direito de propriedade, dos respectivos institutos que a asseguram seu exercício, bem como aqueles associados à propriedade agrária, e as limitações que restringem sua fruição, que serão escopo de abordagem nos tópicos seguintes.

\subsection{O Direito de Propriedade Geral e Agrária}

A propriedade caracteriza-se como toda relação jurídica de apropriação que incide sobre certo bem corpóreo ou incorpóreo. Segundo Sílvio Rodrigues, dentro do sistema de apropriação de riqueza em que vivemos, a propriedade representa a espinha dorsal do direito privado, pois na disputa de bens é que se manifesta o conflito de interesses entre os homens, na quase generalidade dos casos, devendo o ordenamento jurídico procurar disciplinar tais relações. ${ }^{1}$

No mesmo sentido, César Fiúza menciona que a propriedade é a situação jurídica consistente em uma relação dinâmica e complexa entre uma pessoa, o dono, e a coletividade, em virtude da qual são assegurados àquele os direitos exclusivos de usar, fruir, dispor e reivindicar um bem, respeitados os direitos da coletividade. ${ }^{2}$

\footnotetext{
${ }^{1}$ RODRIGUES, Sílvio. Direito civil - Direito das coisas. 26a ed. São Paulo: Saraiva, 2001, p. 73.

${ }^{2}$ FIUZA, César. Direito Civil: Curso Completo. 14ª ed. Belo Horizonte: Del Rey, 2010, p. 766/767.
} 
A propriedade privada representa a ideia de algo perene, permanente, durável, estável, peculiar e particular. São qualidades vinculadas a uma coisa e que a ela pertence. Maria Helena Diniz menciona que conceituar a propriedade é uma árdua tarefa, pois é impossível enumerar a infinita gama de poderes do proprietário. ${ }^{3}$

Segundo Orlando Gomes, a propriedade é o mais amplo dos direitos reais e o mais vasto direito de utilização econômica das coisas, direta ou indiretamente. O proprietário tem a faculdade de servir-se da coisa, retirar frutos e produtos e dar a destinação que lhe aprouver exercendo, assim, poderes jurídicos tão dilatados que a enumeração deles seria impossível ${ }^{4}$.

A propriedade trata-se de relação jurídica complexa, nas palavras de Francisco Eduardo Loureiro, que tem por conteúdo as faculdades de uso, gozo e disposição da coisa por parte do proprietário, subordinadas à função social e com correlatos deveres, ônus e obrigações em relação a terceiros. ${ }^{5}$

No plano normativo, o direito de propriedade no ordenamento pátrio é assegurado como garantia fundamental pela Constituição Federal de 1988, art. 5, XXII. Sua posição de importância fez com que constasse também no caput do artigo $5^{\circ}$, que trata dos direitos e deveres individuais e coletivos da Carta Política. O Código Civil Brasileiro, também delineou os contornos jurídicos do direito de propriedade no seu artigo 1.228.

Conforme José Afonso da Silva, a Constituição consagra a tese de que a propriedade não constitui uma instituição única, mas várias instituições diferenciadas, em correlação com os diversos tipos de bens e de titulares, de onde ser cabível falar não em propriedade, mas em propriedades. $^{6}$

No ordenamento brasileiro o direito de propriedade esta encartado no caput do artigo 1.228 do Código Civil, que dispõe os elementos constitutivos que caracterizadores da qualidade de proprietário: aquele que tem a faculdade de usar, gozar e dispor da coisa, e o direito de reavê-la do poder de quem quer que injustamente a possua ou detenha.

Para este estudo, a propriedade agrária servirá de objeto especial de estudo por possuir importância de destaque para as sociedades, pois pelo cultivo e adequada utilização da terra, que se dá com a atividade agrária, assegura-se a produção de alimentos e circulação de

\footnotetext{
${ }^{3}$ DINIZ, Maria Helena. Curso de Direito Civil Brasileiro, v 4. 25 a ed. São Paulo: Saraiva, 2010, p. 113.

${ }_{5}^{4}$ GOMES, Orlando. Direitos Reais. 19a ed. São Paulo: Forense, 2004, p. 97.

5 LOUREIRO, Francisco Eduardo. Código Civil Comentado: doutrina e jurisprudência. $4^{\text {a }}$ ed. Barueri, SP: Manole, 2010, p. 1196.

${ }^{6}$ Curso de Direito Constitucional Positivo. 10ª ed., São Paulo: Malheiros1994, p. 266.
} 
riquezas. Como bem de produção, a terra possui potencial de utilização voltada à produção de outros bens de uso, consumo ou produção. ${ }^{7}$

A terra, embora possa conferir pleno domínio a seu proprietário, sob a ótica dos conceitos de propriedade anteriormente mencionados, possui características próprias que impossibilita sua utilização se dê de forma irrestrita. Como se trata de um bem que não pode ser produzido ou criado, ao longo da história houve a necessidade de implementar institutos jurídicos de proteção que serviram tanto para preservar o direito de propriedade a seus titulares, quanto à própria propriedade em si considerada.

O Estatuto da Terra (Lei Federal 4.504/1964), Estatuto da Terra é considerado a lei básica do Direito Agrário pátrio, ao lado da Lei Federal 8.629/93, Lei Agrária, que regula os direitos e obrigações concernentes aos bens imóveis rurais, para os fins de execução da reforma agrária e promoção da Política Agrícola.

O critério da destinação do imóvel para a produção de atividades agrárias é o adotado para caracterizar o imóvel rural. Assim, onde houver a atividade explorativa que se configure como agrária, haverá terra rural, de forma contrária, onde for encontrada atividade considerada urbanística, haverá solo urbano, considerando, para tanto, a atividade exercida no imóvel, pouco importando onde esteja localizado. ${ }^{8}$ Realizadas as delimitações do direito de propriedade e a caracterização do imóvel agrário, objeto de estudo, faz-se necessária a identificação conceitual e dos princípios jurídicos aplicáveis à propriedade agrária, circunscritos pelo Direito Agrário. Isso porque dada a particularidade de tratamento conferida pela Constituição Federal e legislação infraconstitucional à propriedade agrária, verifica-se uma estruturação de institutos jurídicos próprios.

\subsection{O Direito Agrário: atividade agrária e a função social}

O Direito Agrário alçou legítima autonomia, de forma que a própria Constituição Federal, em seu artigo 22, inciso I, o posicionou ao lado de outros importantes e consolidados ramos do Direito. Assim, o Direito agrário enquanto ramo autônomo, requer uma conceituação que considere o dinamismo de suas interações sociais e econômicas.

Nessa perspectiva, Paulo Torminn Borges define o Direito Agrário como um conjunto sistemático de normas jurídicas que visam disciplinar as relações do homem com a

\footnotetext{
${ }^{7}$ REZEK, Gustavo Elias Kallás. Imóvel agrário: agrariedade, ruralidade e rusticidade. Curitiba: Juruá, 2007, p.

${ }^{25}$ BORGES, Paulo Torminn. Institutos básicos do Direito Agrário. 10. ed. São Paulo: Saraiva, 1996, p. 30.
} 
terra, tendo em vista o progresso social e econômico do rurícola e o enriquecimento da comunidade ${ }^{9}$. Neste conceito, o autor deixa de inserir os princípios que visam a disciplinar as relações do homem com a terra. ${ }^{10}$

Para o doutrinador argentino Antônio Carlos Vivanco, o Direito Agrário é o ordenamento jurídico que rege as relações sociais e econômicas, que surgem entre os sujeitos intervenientes na atividade agrária. $\mathrm{O}$ conceito de direito refere-se ao ordenamento normativo e coativo, tendente a regular a conduta humana dentro do grupo social, e agrário significa a terra com aptidão produtiva e a toda atividade vinculada com a produção agropecuária. ${ }^{11}$

Fernando Pereira Sodero considera o Direito Agrário como um conjunto de princípios e de normas, de Direito Público e de Direito Privado, que visa a disciplinar as relações emergentes da atividade rural, com base na função social da terra ${ }^{12}$. O autor propõe uma dicotomia proposta entre Direito Público e Direito Privado, sendo o mais adequando falar-se normas imperativas ou cogentes e supletivas. ${ }^{13}$

Por meio das definições apresentadas pelos autores, destacam-se essencialmente dois elementos para a formação do conceito: atividade agrária, considerada como a relação homem-terra que visa a produção de alimentos, e a função social da terra. E assim se estrutura o Direito Agrário, por meio de um conjunto de princípios e de normas que disciplinam as relações associadas à atividade agrária, tendo por fundamento a função social da terra.

Por essa razão, ao lado das garantias ao direito de propriedade mencionadas, o próprio texto constitucional brasileiro vigente exige o cumprimento da função social da propriedade privada (art. 170, III da CF), como se analisará adiante. Com isso, o direito de propriedade não é um direito absoluto e o proprietário tem o dever de conferir uma função social à propriedade (art. 5\% XXIII, da CF). Quanto à conceituação de atividade agrária, segundo Gustavo Rezek, considera a atividade humana de cultivo de vegetais e de criação de animais, caracterizada pela presença de um processo orgânico de desenvolvimento desses vegetais e animais, sujeitos às leis naturais e, portanto, não totalmente controlado pelo homem, cujos produtos, sendo coisas, são destinados ao consumo social em sentido amplo, ou seja, não somente ao consumo alimentar. ${ }^{14}$

\footnotetext{
9 Institutos Básicos do Direito Agrário. 10. ed. São Paulo: Saraiva, 1996, p. 14

${ }^{10}$ Ibid., p. 36

11 VIVANCO, Antônio Carlos. Teoría de Derecho Agrario, La Plata: Ediciones Librería Jurídicas, 1967, p. 184

12 SODERO, Fernando Pereira; Direito Agrário e Reforma Agrária, Livraria Legislação Brasileira Ltda., São Paulo, 1968, p. 32

14 REZEK, Gustavo Elias Kallás. Imóvel agrário: agrariedade, ruralidade e rusticidade. Curitiba: Juruá, 2007, p. 29-30.
} 
Segundo o autor, pela Teoria da Agrariedade a propriedade deve contar com a presença de terra fértil, vegetais ou animais e da ação humana ao viabilizar o ciclo agrobiológico de crescimento voltado ao consumo da sociedade ${ }^{15}$. Quanto ao ciclo agrobiológico, conforme Gustavo Rezek, se pressupõe a existência de organismos vivos e a interferência da atividade humana sobre tais organismos acompanhando o processo orgânico. $^{16}$

A distinção da uma atividade como agrária de outras desenvolvidas pelo homem, conforme ensinamentos de Giselda Hironaka, está no reconhecimento do processo agrobiológico que aquela exige, no momento em que por meio do trabalho humano, tendo como meta a obtenção de frutos ou produtos, a interferência do homem na terra resulta na produção no campo. ${ }^{17}$

Referente à função social, o doutrinador Paulo Torminn Borges não a trata como sendo dever da propriedade, mas sim dever da própria terra, conferindo-a a concepção de que a propriedade destina-se a atender aos fins humanos, de funções individuais, familiares e sociais para que seja possível cultivar eficiente e corretamente a terra. ${ }^{18}$

Prossegue o autor que o proprietário que faça a terra produzir como mãe dadivosa e fértil, mas sem a exaurir, sem a esgotar, porque as gerações futuras também querem tê-la produtiva. O proprietário precisa trabalhar a terra, ou faze-la trabalhada. Proprietário que tem responsabilidade pelo bem-estar dos que, com ele, labutam na terra. ${ }^{19}$

Nessa perspectiva, relação de titularidade em face da função social da propriedade, passa por uma noção de coletividade. Conforme Sílvio de Salvo Venosa, estabelecer o equilíbrio e a proporcionalidade da relação individual com a obrigação coletiva configura o limite e a razão existencial do direito de propriedade na nova ordem jurídica contemporânea. $^{20}$

A Constituição Federal considera princípio ou direito fundamental a função social da propriedade. A Carta Magna estabeleceu do artigo 186 regras específicas para auferir o cumprimento da função social da propriedade, conforme critérios e graus de exigência estabelecidos em lei.

\footnotetext{
${ }^{15}$ Ibid., p.30-31.

${ }^{16}$ Ibid., p. 31.

${ }^{17}$ HIRONAKA, Giselda Maria Fernandes Novaes. Atividade agrária e proteção ambiental: simbiose possível. São Paulo: Cultural Paulista, 1997, p. 31.

${ }^{18}$ BORGES, Paulo Torminn. Institutos básicos do Direito Agrário. 10. ed. rev. e ampl. São Paulo: Saraiva, 1996,

${ }^{20}$ VENOSA, Sílvio de Salvo. Direitos reais. São Paulo: Atlas, 2001, p. 141.
} 
A função social da propriedade do imóvel agrário é estabelecida pelo Estatuto da Terra de 1964 (Art. $2^{\circ}$ ) e Lei Agrária (Art. 9º, que pode ser aferida sobre as óticas social, econômica, ambiental e trabalhista.

Embora a legislação infraconstitucional defina os critérios de apuração da função social, critica-se que o controle desse cumprimento, a cargo do Instituto Nacional da Colonização e Reforma Agraria - INCRA, é centrado, via de regra, apenas na produtividade do imóvel, por meio do Grau de Utilização da Terra e Grau de Eficiência. Os demais critérios de apuração da função social são pouco considerados, o que pode conduzir à falsa ideia que função social se alcança pelo atendimento apenas da produtividade.

Traçados os contornos jurídicos incidentes sobre o imóvel agrário, as atividades nele desenvolvidas e as exigências quanto ao cumprimento da função social, se passará a uma análise mais detida das limitações impostas ao exercício da propriedade, em especial através da instituição de servidão administrativa.

\subsection{Limitações ao Exercício do Direito de Propriedade e a Servidão Administrativa}

No contexto contemporâneo de estado de direito, o exercício do direito de propriedade não é absoluto e irrestrito. Mas dada a relevância do instituto 'propriedade' e seus reflexos não só para a economia, mas para a própria segurança jurídica, a própria Constituição estabelece as exceções ao seu exercício pleno.

Dentre as formas mais agudas que levam à perda da propriedade esta a desapropriação, procedimento pelo qual o Poder Público compulsoriamente retira de alguém a sua propriedade. Dentre as formas de desapropriação estão as declaradas por necessidade ou utilidade pública.

O Decreto-Lei $n^{\circ}$ 3.365/1941 disciplina as desapropriações por utilidade pública, que possui previsão constitucional. Já a lei $\mathrm{n}^{\circ} 4.132 / 1.962$ trata de desapropriação por interesse social. Ambos os diplomas normativos estabelecem os pressupostos, requisitos e condições diferenciadores de cada um dos institutos que formas que autorizam a desapropriação.

Há ainda uma forma de expropriação de glebas onde forem localizadas culturas ilegais de plantas psicotrópicas ou a ex ração de trabalho escravo. Por não indenizar o proprietário expropriado, trata-se de verdadeira sanção ou confisco. Essa modalidade de expropriação, além de dar a devida função social à propriedade, busca também reprimir o tráfico ilícito de entorpecente. 
Desapropriação para fins de reforma agrária realizada por interesse social também está prevista no texto constitucional, artigo 184, juntamente as limitações, artigo 185.

Requisição da propriedade no caso de iminente perigo público é uma das hipóteses constitucionais de limitação temporária do exercício da propriedade. No que se refere à propriedade agrária, sua ocorrência se dá de forma mais episódica, e em geral só atinge parcela do imóvel, apresentado distinções importantes em relação ao que ocorre com imóveis urbanos.

Quanto às servidões administrativas, tratam-se restrições que consistem em um dever de suportar pelo proprietário, no que se refere ao domínio pleno da propriedade. Tratase de restrições das faculdades de uso e fruição do direito de propriedade a favor de uma entidade pública, com escopo de servir ao uso público. ${ }^{21}$

Conforme ensinamentos de Hely Lopes Meirelles, a servidão administrativa ora tratada refere-se a um ônus real do Poder Público sobre a propriedade particular, com finalidade de serventia pública, diferindo da servidão de direito civil, que trata do direito real de um prédio em relação a outro, com a finalidade de serventia privada. ${ }^{22}$

Para Maria Sylvia Zanella Di Pietro, no conceito de servidão é essencial a presença de dois elementos: a coisa serviente e a coisa dominante, a primeira prestando utilidade à segunda. Eliminar do conceito de servidão administrativa a coisa dominante significa desnaturar o instituto tal qual tem sido concebido desde o direito romano e dar-lhe amplitude tão grande que abrangerá todas as restrições impostas pelo poder público à propriedade privada. ${ }^{23}$

A servidão administrativa pode ser instituída, segundo Hely Lopes Meirelles, por acordo administrativo ou por sentença judicial, precedida de ato declaratório da servidão. E para dar conhecimento a terceiros e eficácia erga omnes, deve ser devidamente registrada, nos termos da Lei de Registros Públicos (Lei 6.015/73). Haveria assim, impossibilidade da instituição por lei da servidão, visto que esta deve decorrer de um ato administrativo concreto e determinado. $^{24}$

\footnotetext{
${ }^{21}$ MELLO, Celso Antônio Bandeira de. Apontamentos sobre o poder de polícia. Revista de Direito Público no 9 , p. 61.

${ }^{22}$ MEIRELLES, Hely Lopes. Direito Administrativo Brasileiro. 22. ed. São Paulo: Malheiros, 1997, p. 537 e 538.

${ }^{23}$ DI PIETRO, Maria Sylvia Zanella. Direito administrativo. 20. ed. São Paulo: Atlas, 2007, p.136.

${ }^{24}$ MEIRELLES, op. cit., p. 539.
} 
Maria Sylvia sustenta que as servidões administrativas podem tanto se constituir mediante acordo e sentença judicial, como decorrer diretamente da lei, quando, então, não se faria necessário o registro da servidão administrativa. ${ }^{25}$

Hely Lopes Meirelles afirma que a servidão administrativa é ônus real de uso imposto pela Administração à propriedade particular para assegurar a realização e conservação de obras e serviços públicos ou de utilidade pública, mediante indenização dos prejuízos efetivamente suportados pelo proprietário. ${ }^{26}$

Assim, para o recebimento de indenização deve estar configurada a redução do potencial econômico da propriedade, decorrente de um ato administrativo específico ${ }^{27}$.

Ao contrário do que ocorre na desapropriação, na servidão o proprietário mantém a titularidade da propriedade, e somente deve ser indenizado se sofrer prejuízos, sob pena de enriquecimento ilícito. Caso a servidão derive de lei, os proprietários prejudicados não farão jus à referida indenização em nenhuma hipótese, por se tratar de sacrifício imposto a toda uma coletividade de imóveis que se encontram na mesma situação. $^{28}$

Assim, quando caraterizada a situação de redução da disponibilidade plena e exclusiva do bem pelo proprietário, cujo direito é sacrificado com o ato administrativo específico, surge o direito em ser devidamente indenizado.

Por fim, as servidões administrativas são distintas das limitações administrativas que incidem sobre a propriedade. Para estas últimas, o ato administrativo que as instituem tem caráter genérico. Assim, a restrição de construção de edifícios até certa altura, sendo uma obrigação genérica de não fazer, é uma limitação administrativa ao direito de construir. Por outro lado, a obrigação de suportar a passagem de fios elétricos sobre o terreno de uma determina propriedade é uma servidão administrativa porque onera diretamente o imóvel afetado com uma serventia pública. ${ }^{29}$

A servidão se caracteriza quando o proprietário tiver que suportar determinado acontecimento, ou certa restrição de seu direito de propriedade que implique no efetivo sacrifício de seu direito de propriedade, e em um ônus real ${ }^{30}$.

\footnotetext{
${ }^{25}$ DI PIETRO, op. cit., p. 137.

${ }^{26}$ MEIRELLES, op. cit., p. 537.

${ }^{27}$ MEIRELLES, op. cit., p. 540.

${ }^{28}$ DI PIETRO, Maria Sylvia Zanella. Direito administrativo. 20. aed. São Paulo: Atlas, 2007, p. 145.

${ }^{29}$ MEIRELLES, Hely Lopes. Direito administrativo brasileiro. 22. ed. São Paulo: Malheiros, 1997, p. 538.

${ }^{30}$ MELLO, Celso Antônio Bandeira de. Curso de direito administrativo. 17. ed. São Paulo: Malheiros, 2004, p. 799.
} 
A declaração de utilidade pública ou interesse social é a manifestação pública da vontade de se intervir em determinada propriedade. A declaração, segundo José Carlos de Moraes Salles, poderá ser feita por decreto do Presidente da República, dos Governadores dos Estados, Distrito Federal e Territórios, de possíveis interventores estaduais ou municipais e dos Prefeitos do Município, bem como por meio de lei, de iniciativa do Poder Legislativo federal, estadual ou municipal. ${ }^{31}$

Uma vez emitida, decorrem os efeitos enumerado por Celso Antônio Bandeira de Mello, como i) a submissão do bem à força expropriatória do Estado; ii) a fixação do estado do bem; iii) a concessão ao Poder Público do direito de penetrar no bem a fim de fazer verificações; iv) a iniciação do prazo de caducidade da declaração. ${ }^{32}$

Feitas as considerações quanto ao direito de propriedade e aos requisitos que autorizam a intervenção estatal, passa-se à analise dos efeitos pecuniários resultantes das intervenções em terras que não cumprem a função social.

\section{A INDENIZAÇÃO DE TERRAS PRODUTIVAS QUE NÃO CUMPREM A FUNÇÃO SOCIAL}

Como visto anteriormente, para se assegurar o exercício do direito de propriedade, esta deve alcançar sua função social. A própria Constituição assegura o direito e disciplina o modo de aferição de tais condições.

Cumpre inicialmente apontar uma aparente antinomia contida no texto constitucional. O artigo 185, inciso II da Constituição Federal estabelece que seja insuscetíveis de desapropriação para fins de reforma agrária a propriedade produtiva. Como tratado, a propriedade não pode ser considerada isoladamente, mas deve atender a uma função social, cujos critérios estão estabelecidos na própria Constituição, artigo 186.

O embate doutrinário e que chega com teses diversas ao Judiciário seria o caráter meramente programático do 185 , II, nos casos que mesmo produtiva, uma propriedade não cumpra a função social.

\footnotetext{
${ }^{31}$ A desapropriação à luz da doutrina e da jurisprudência. 5. ed. São Paulo: Revista dos Tribunais, 2006, p. 141.

${ }^{32}$ MELLO, op. cit., p. 772.
} 
José Afonso da Silva afirmam que o art. 185, II impede uma sanção mais radical a propriedades que produzam, mesmo com crimes ambientais ou trabalho escravo, ao afirmar que a proibição de desapropriação da propriedade produtiva absoluta, "sendo inútil procurar interpretação diferente com base em nossos desejos. Isso não seria científico", 33

Ocorre que a produtividade não é um atributo suficiente para vestir qualquer propriedade com o manto da intangibilidade, tornando-a insuscetível de desapropriação. A aparente antinomia constitucional precede da exigência do atendimento da função social da propriedade, o que implica a satisfação de requisitos econômicos, sociais e ecológicos. E como tratado anteriormente, as civilizações tem superado a concepção do uso e abuso pleno, soberano e individual da propriedade.

Por isso não pode o constituinte ter querido criar um tipo de propriedade que não cumpre a função social e ainda assim imune aos atos desapropriatórios para fins de reforma agrária. Antes, determinou ainda que o legislador ordinário o dever de estabelecer regras para que venha a cumprir essa função.

Mas ainda resta responder o qual seria a definição jurídica de propriedade produtiva. Para o Instituto Nacional de Colonização e Reforma Agrária - INCRA, o imóvel (propriedade agrária) é considerado produtivo quando explorado econômica e racionalmente, atinge, simultaneamente, graus de utilização da terra (GUT) e de eficiência na exploração (GEE) segundo índices fixados pelo órgão federal competente. O Grau de Utilização da Terra (GUT), deverá ser igual ou superior a $80 \%$ (oitenta por cento) e o Grau de Eficiência na Exploração da terra (GEE), deverá ser igual ou superior a $100 \%$ (cem por cento). Tais critérios de aferição estão contidos em Instrução Normativa No 11/2003.

O professor Carlos Frederico Marés, ao pontuar sobre a questão da função social, assinala que a lei, a partir da norma constitucional, não admite que o direito de propriedade não seja exercido, que a terra não seja usada. Na interpretação literal da Constituição de 1988, não cumpre a função social quando a propriedade não tem aproveitamento racional e adequado. ${ }^{34}$ E continua demonstrando que há uma evidente ilegalidade ao não usar, isto é não realizar na prática o direito de propriedade. Mas não é só isso, ainda em análise literal, ao usar haverá de fazê-lo segundo as regras, critérios e graus que a lei especifica, portanto é

\footnotetext{
33 SILVA, José Afonso da. Comentário Contextual à Constituição. 3a. Edição. São Paulo: Malheiros, 2007, p. 747.

${ }^{34}$ MARÉS, Carlos Frederico. Desapropriação sanção por descumprimento da função social? Revista de Direito Agrário / Instituto Nacional de Colonização e Reforma Agrária. Ano 19, n 18. 2006, p. 67.
} 
incontestável a obrigação do proprietário. Qual é a consequência jurídica de não o fazer ou fazer mal, de não cumprir a obrigação? A terra pode ser desapropriada pelo Poder Público Federal para fins de reforma agrária, pois desatende as razões do estabelecimento de condições para o uso da terra.

Marés conclui que desde o início do século XX não se admite que uma terra, dentro da fronteira agrícola, isto é, que disponha de investimentos públicos como estradas e formas de escoamento da produção, não produza. E a razão é a segurança alimentar. É necessário produzir alimentos, mas, mais do isto é necessário produzir riquezas, para que seja possível por meio dos salários e da intervenção do Poder Público na aplicação das políticas públicas garantidas pelos impostos gerados pela riqueza, fazer com que todos vivam com dignidade e felicidade.

Os professores Luiz Carlos Falconi e José Nicolau Heck, fazem uma brilhante diferenciação entre o artigo sobre propriedade produtiva versus cumprimento de função social, lecionam que diante das disposições constitucionais e regulamentares, há nítida distinção entre propriedade produtiva e propriedade destrutiva. Enquanto uma se limita a produzir na área agricultável, outra investe sobre as áreas especialmente protegidas, ao arrepio da função ambiental da propriedade, e por conseguinte, da função social em si. ${ }^{35}$

Assim, o direito de propriedade não representa o exercício de forma plena e inquestionável pelo proprietário. O Código Civil, no parágrafo primeiro do artigo 1.228, elenca de forma não taxativa, bens jurídicos que relativizam o direito de propriedade, que deve ser exercido em consonância com as suas finalidades econômicas e sociais como o equilíbrio ecológico ou o patrimônio histórico e artístico.

Segundo Maria Celina Bodin de Moraes, trata-se de uma estrutural transformação do conceito de direito civil, ampla o suficiente para abrigar, na tutela das atividades e dos interesses da pessoa humana, técnicas e instrumentos tradicionalmente próprios do direito público como, por exemplo, a aplicação direta das normas constitucionais nas relações jurídicas de caráter privado. ${ }^{36}$

Para a autora, a inflexão da disciplina civilista (voltada anteriormente para a tutela dos valores patrimoniais) em obediência aos enunciados constitucionais, os quais não mais

\footnotetext{
35 FALCONI, Luiz Carlos e HECK, José Nicolau A depredação das áreas de preservação permanente e de reserva legal florestal do bioma Cerrado como causa de desapropriação da propriedade rural por interesse social. Revista de Informação Legislativa. Brasília a. 42 n. 168 out./dez. 2005, p. 75-100.

${ }^{36}$ MORAES, Maria Celina Bodin de. A Caminho de um Direito Civil Constitucional. In: Revista de Direito Civil, $n^{\circ} .65$ (1993), p. 29.
} 
admitem a proteção da propriedade e da empresa como bens em si, mas somente enquanto destinados a efetivar valores existenciais, realizadores da justiça social. ${ }^{37}$

Trata-se de uma abordagem que considera não a indenização de uma propriedade em si considerada, mas se essa cumpre uma função social segundo os princípios constitucionais e direitos fundamentais que requeira ser indenizada por qualquer intervenção estatal. Nessa perspectiva, os institutos jurídicos, e que se inclui os conceitos de propriedade privada e a indenização desapropriatória, devem ser norteados para a construção permanente de uma sociedade justa, livre e solidária.

Refere-se de uma nova teoria do domínio, que reformula os aspectos internos (usar, gozar e dispor) da propriedade, com seus aspectos externos, representados pela de relação jurídica com a coletividade de não-proprietários, reconhecida na efetivação da função social dada a ele ${ }^{38}$. Conforme leciona Gustavo Tepedino, a relação jurídica de propriedade passa a possuir interesse extraproprietários, moldadas pela função social, e quando não observada, não pode ser tutelada pelo ordenamento jurídico. ${ }^{39}$

Com a relativização propriedade privada, há reflexos no instituto da indenização, que deve ser ajustada a uma lógica jurídica mais adequada, a implementação de um "programa social". 40

A Constituição de 1988 assegura a garantia do atendimento à função social da propriedade como direito fundamental e não como mero limite extrínseco à propriedade privada (art. $5^{\circ}$, XXIII). No título VII, que trata da Ordem Econômica e Financeira, o princípio da função social da propriedade, requer o cumprimento do 'bem estar dos habitantes' (art. 182, caput), o 'bem estar dos proprietários e dos trabalhadores' (art. 186, IV), isso tudo depois de ter incluído a mesma função social da propriedade no capítulo I do título II - dos direitos e deveres individuais e coletivos (art. $5^{\circ}$, XXIII) - resguardando os últimos em cláusulas pétreas (art. $\left.60, \S 4^{\circ}, \mathrm{IV}\right) .^{41}$

$\mathrm{O}$ que se pretende analisar são as indenizações das terras em que se pretende alguma intervenção estatal, como a instituição de servidões administrativas, não obstante

\footnotetext{
${ }^{37}$ MORAES, op. cit., p. 29.

38 ARONNE, Ricardo. Por uma Nova Hermenêutica dos Direitos Reais Limitados. Rio de Janeiro: Renovar, 2000 .

39 TEPEDINO, Gustavo. Contornos Constitucionais da Propriedade Privada. In: Temas de Direito Civil. Rio de Janeiro: Renovar, 2004, p. 318-320.

${ }^{40}$ TEPEDINO, Gustavo. Contornos Constitucionais da Propriedade Privada. In: Temas de Direito Civil. Rio de Janeiro: Renovar, 2004, p. 322.

41 ALFONSIN, Jacques Távora. O Acesso à Terra como conteúdo de direitos humanos fundamentais à alimentação e à moradia. Porto Alegre: Sergio Antônio Fabris Editor, 2003, p. 206.
} 
possuírem produtividade socialmente nociva. Considera-se produtividade não no sentido estrito econômico ou lucrativo, mas no sentido dos princípios constitucionais que importa produtividade social e ambiental.

Com o Parecer Conjunto CPALNP-CGAPJP/CJ/MDA 011/2004 ${ }^{42}$, a propriedade agrária, simplesmente por ser economicamente produtiva, não estaria livre de cumprir sua função social, devendo a autarquia responsável pela reforma agrária verificar também as condições trabalhistas e ambientais do imóvel, aplicando o procedimento da desapropriaçãosanção quando este não atingir patamares satisfatórios também nesses aspectos.

Segundo o Professor Marés, tais propriedades não só carecem de proteção jurídica, como o Estado tem obrigação de retirar das mãos de seus proprietários, mesmo que a produção seja em regime de contrato agrário. A propriedade produtiva que não cumpre a função social sequer pode ser desapropriada, deve seguir a linha das produtoras de psicotrópicos e ser expropriadas sem pagamento de indenização. Arremata o autor que independentemente das consequências de ordem penal que possa advir para o proprietário, haverá de ter consequências civis para o direito de propriedade. ${ }^{43}$

É justamente a sua função justifica e legitima essa propriedade ${ }^{44}$. Sem legitimação não existe propriedade, o proprietário tem a obrigação de cumprir o determinado, é um dever do direito, e quem não cumpre seu dever, perde seu direito. ${ }^{45}$

Conforme Boaventura de Sousa Santos, todo Estado com vocação de sobrevivência deve estar atento a exigências da realidade social. Assim, o Estado deve atuar para garantir o direito privado e disponível à propriedade, mediante a apuração de que esta efetivamente esteja cumprindo sua função social. ${ }^{46}$

Não havendo a expropriação de propriedades rurais que tenham ilícitos ambientais e trabalhistas, outro ponto a ser observado refere-se ao preço justo e preço de mercado, no caso das indenizações para propriedades em que se encontra em tais situações.

\footnotetext{
42 PARECER CONJUNTO/CPALNP-CGAPJP/CJ/MDA/Nº 011/2004 (VAF/JMPJ). Desapropriação para fins de reforma agrária produtividade obtida mediante infração ou abuso fundamento nos incisos II, III e IV do art. 186 da CF/88. Disponível em: <http://www.oit.org.br/sites/all/forced_labour/legis_jur/temasdiversos/ PARECER\%20AMBIENTAL-REVISTO-31122004-011-2004-CPALNP-CGAPJP-CO.pdf $>$. Acesso em 30/11/2014.

${ }^{43}$ MARÉS, Carlos Frederico. A Função Social da Terra. Porto Alegre: Sergio Antonio Fabris Editor, 2003 , p. 129.

${ }^{44}$ GRAU, Eros Roberto. A ordem econômica na Constituição Federal de 1988. 13. ed. São Paulo: Malheiros, 2008, p. 260.

${ }^{45}$ MARÉS, op. cit., p. 73.

${ }^{46}$ SANTOS, Boaventura de Sousa. O Estado e o direito na transição pós-moderna: para um novo senso comum. Coimbra-PT: Revista Crítica de Ciências Sociais, N.30, 1990, p. 270.
} 
Assim, o preço de mercado deve ser um critério de avaliação da indenização, entretanto, não deve ser o único critério de aferição do preço justo a ser pago. Indenizar uma propriedade que descumpre a legislação trabalhista ou ambiental por preço de mercado seria ignorar a conduta do proprietário, desnaturando a essência do instituto.

A imposição administrativa de uma sanção, pelo descumprimento do dever, que incumbe a todo proprietário, de dar a certos e determinados bens uma destinação social. Seria antijurídico atribuir ao expropriado que agiu com abuso do direito de propriedade uma indenização completa, correspondente ao valor venal do bem mais juros compensatórios.

A Constituição, aliás, tanto no art. $5^{\circ}$, XXIV, quanto no art. 182, $\S 3^{\circ}$, e no art. 184 requer justa indenização, e não indenização pelo valor de mercado. Ressarcir integralmente aquele que descumpre o seu dever fundamental de proprietário é proceder com manifesta injustiça. $^{47}$

Recebendo o proprietário indenização inferior ao seu ativo patrimonial, caracteriza-se abuso praticado pelo Estado, que poderá ser inclusive instado judicialmente a promover a complementação que for devida. Por outro lado, recebendo o proprietário além de seu ativo patrimonial, tem-se o enriquecimento sem causa ou enriquecimento ilícito do particular, havendo para tal vedação expressa no Código Civil. Assim, a busca de equilíbrio nessa compensação se dá com a fixação do preço justo. Sendo for injusto o preço, para qualquer lado, haverá enriquecimento sem causa, vedado pelo direito. ${ }^{48}$

$\mathrm{Ou}$ seja, é enriquecimento ilícito, no ordenamento brasileiro, qualquer ganho material que aconteça em prejuízo de outrem (nem que seja o Estado, que é simplesmente uma organização do erário, que pertence à coletividade), sem origem jurídica válida. Trata-se de instituto que se dá sem origem jurídica, em prejuízo de outrem. O que separa o enriquecimento juridicamente permitido, fundado em fato jurídico lícito, do enriquecimento sem causa é a licitude. ${ }^{49}$

Assim, no caso de descumprimentos da função social em seus aspectos ambientais e trabalhistas, existe uma diminuição no valor social do imóvel agrário que deve ter reflexos econômicos. Logo, qualquer indenização que o Estado realize em um imóvel que tenha um

\footnotetext{
${ }^{47}$ COMPARATO, Fábio Konder. Direitos e Deveres em Matéria de Propriedade. In: STROZAKE, Juvelino (org.). A Questão Agrária e a Justiça. São Paulo: Editora Revista dos Tribunais, 2000, p. 145.

48 MARÉS, Carlos Frederico. Desapropriação sanção por descumprimento da função social? Revista de Direito Agrário / Instituto Nacional de Colonização e Reforma Agrária. Ano 19, n 18. 2006, p. 75.

${ }^{49}$ LÔBO, Paulo Luiz Netto. Dos Contratos em Geral. In: PEREIRA, Rodrigo da Cunha (org.) Código Civil Anotado. Porto Alegre: Síntese, 2004, p. 591.
} 
passivo ambiental a ser restaurado ou infrações trabalhistas que repercutam em danos coletivos, terá que ser feita, necessariamente abaixo do preço de mercado ${ }^{50}$.

Da mesma forma que configura uma injustiça flagrante o Estado remunerar abaixo do preço de mercado ao proprietário que em nada descumpriu sua função social, também configura igual injustiça remunerar a preço de mercado o proprietário que desvalorizou socialmente a terra que tinha a obrigação de cuidar.

Para restaurar o status quo ante, medida de impreterível justiça, o Estado deverá investir recursos na recuperação ambiental da área degradada (no caso do descumprimento ambiental) ou na recuperação social da região em que o imóvel se encontra (no caso de descumprimento trabalhista). Tais recursos devem, então, necessariamente, ser descontados do valor da indenização, e investidos na recuperação ambiental ou em projetos econômicos e sociais de fomento na região do imóvel.

\section{CONCLUSÃO}

Ao longo do desenvolvimento do trabalho, demostrou-se que o direito à propriedade privada esta presente e de forma marcante no direito e na realidade brasileira. Os institutos de proteção estão assegurados no texto constitucional, que tratou como cláusula pétrea (artigo 60, parágrafo $4^{\circ}$ ) a garantia ao direito de propriedade (artigo $5^{\circ}, \mathrm{XXII}$ ), sendo que o Código Civil, que delineou os contornos jurídicos para o exercício do direito de propriedade e no seu artigo 1.228.

Para se destacar o amparo normativo reservado à propriedade agrária dentro dos ramos do Direito, abordou-se a conceituação e objeto de estudo do Direito Agrário. Para a conceituação de Direito Agrário, lançando mão de doutrinadores consagrados, foram pontuados os elementos que cada um considera como relevante.

Evidenciou-se ainda o princípio da função social da propriedade, que passa por uma noção de coletividade, que nas palavras de Sílvio de Salvo Venosa, a razão existencial do direito de propriedade na nova ordem jurídica contemporânea é o equilíbrio entre o interesse coletivo e o interesse individual, o que nem sem sempre é alcançado pela legislação.

Tal princípio está encartado na Constituição (artigo $5^{\circ}, \mathrm{XXIII)}$ ), estabelecendo os critérios de aferição (artigo 186), e coube ao Estatuto da Terra de 1964 e à Lei Agrária,

\footnotetext{
${ }^{50}$ SANTOS, João Paulo de Faria. REFORMA AGRÁRIA E PREÇO JUSTO: A Indenização na Desapropriação para fins de reforma agrária e possibilidades de ruptura do individualismo proprietário. Brasília, 2008. Dissertação (Mestrado) - Faculdade de Direito, Universidade de Brasília, p. 116.
} 
estabelecer critérios e graus de exigência, com ênfase social, econômica, o ambiental e trabalhista.

O Instituto Nacional da Colonização e Reforma Agraria - INCRA - é a entidade responsável pela fiscalização do cumprimento da função social, e criticou-se o fato desta estar centrada basicamente na produtividade do imóvel, pela apuração do Grau de Utilização da Terra e Grau de Eficiência, e sem a consideração dos demais critérios, tem-se pode conduzir à falsa ideia de cumprimento da função social.

Com isso, demonstrou-se que o direito de propriedade é caro para o direito, como garantia de segurança e desenvolvimento, mas não é irrestrito. A propriedade agrária deve atingir o cumprimento da função social, de forma a beneficiar o proprietário e a coletividade. Além disso, o texto constitucional que assegura o direito de propriedade condicionado ao cumprimento da função social, estabeleceu também as exceções para o seu exercício.

Apontou-se a requisição, ocupação temporária, limitação administrativa, servidão, tombamento, desapropriação e o confisco são modalidades de intervenção do Estado na propriedade privada autorizadas pela Constituição. Deteve-se no instituto da servidão administrativa pelo interesse ao presente estudo.

Servidão administrativa é uma restrição ao domínio pleno da propriedade, com finalidade de serventia pública e devendo ser suportada pelo proprietário, que mantém a titularidade da propriedade, suportando o ônus real de uso para assegurar a realização e conservação de obras e serviços públicos ou de utilidade pública, sendo indenizado pelos prejuízos efetivamente que caracterizem a redução do potencial econômico da propriedade.

Com a análise com conteúdo constitucional, afastou-se a aparente antinomia entre o artigo 185, inciso II e o artigo 186 da Constituição Federal, por envolver o caráter programático, ou mesmo como defendido por alguns doutrinadores, a inexistência na Carta Magna de "letra morta".

Na sequencia, passou-se à avaliação do conceito de propriedade produtiva na legislação e se o aproveitamento racional e adequado como caracterizadora do cumprimento da função social, visando entender a necessidade de que a terra produza, gerando riquezas e assegurando a implementação de políticas públicas. Nessa perspectiva, a estrutural transformação do conceito de direito civil, que parte da tutela dos valores patrimoniais individuais, que são postos no prisma da obediência aos enunciados constitucionais, para se efetivar os valores existenciais, realizadores da justiça social. A função social nessa nova tomada de perspectiva implica na relativização da propriedade privada. 
Com esses parâmetros, a propriedade tem um dever em cumprir sua função social, tendo como consequência a mitigação da proteção dos direitos dos proprietários que deixam de observar. As propriedades agrárias que cometam ilícitos, como ambientais e trabalhistas, devem possuir tratamento diferenciado para se apurar o preço justo para fins de indenização quanto à necessidade de alguma intervenção estatal.

Com isso, tem-se o respeito ao direito privado do proprietário, conciliando com os aspectos públicos e constitucionais, levando em consideração que o Estado não pode agir com abuso, pagando ao proprietário indenização inferior ao seu ativo patrimonial, e nem que este receba além de seu ativo patrimonial, caracterizando o enriquecimento sem causa ou enriquecimento ilícito.

Conforme ensina Celso Fiorillo, a busca e a conquista de um ponto de equilíbrio entre o desenvolvimento social, o crescimento econômico e a utilização dos recursos naturais exigem um adequado planejamento territorial que tenha em conta os limites da sustentabilidade. O critério do desenvolvimento sustentável deve valer tanto para o território nacional na sua totalidade, áreas urbanas e rurais, como para a sociedade, para o povo, respeitadas as necessidades culturais e criativas do país. ${ }^{51}$

A Constituição Federal estabelece que a ordem econômica, fundada na livre iniciativa (sistema de produção capitalista) e na valorização do trabalho humano (limite ao capitalismo selvagem), deverá regrar-se pelos ditames de justiça social. Segundo Fiorillo, a ideia principal é assegurar a existência digna da pessoa humana, atreva de uma vida com qualidade.

$\mathrm{O}$ autor se volta para uma abordagem para o princípio da defesa do meio ambiente, contido no inciso VI do Art. 170, ressaltando que o mesmo não objetiva impedir o desenvolvimento econômico, mas exige-se que as atividades sejam desenvolvidas lançando-se mão dos instrumentos existentes adequados para a menor degradação possível. Não obstante, pode-se lançar mão do mesmo raciocínio para integração dos demais dispositivos constitucionais.

\footnotetext{
${ }^{51}$ FIORILLO, Celso Antônio Pacheco. CURSO DE DIREITO AMBIENTAL BRASILEIRO. 14 ed. rev., apl. e atual. em face da Rio+20 e do novo Código Florestal - São Paulo: Saraiva, 2013, p. 79.
} 


\section{REFERÊNCIAS}

ALFONSIN, Jacques Távora. O Acesso à Terra como conteúdo de direitos humanos fundamentais à alimentação e à moradia. Porto Alegre: Sergio Antônio Fabris Editor, 2003.

ARONNE, Ricardo. Por uma Nova Hermenêutica dos Direitos Reais Limitados. Rio de Janeiro: Renovar, 2000.

BORGES, Paulo Torminn. Institutos básicos do Direito Agrário. 10. ed. São Paulo: Saraiva, 1996.

COMPARATO, Fábio Konder. Direitos e Deveres em Matéria de Propriedade. In: STROZAKE, Juvelino (org.). A Questão Agrária e a Justiça. São Paulo: Editora Revista dos Tribunais, 2000.

DI PIETRO, Maria Sylvia Zanella. Direito administrativo. 20. ed. São Paulo: Atlas, 2007.

DINIZ, Maria Helena. Curso de Direito Civil Brasileiro, v 4. 25 a ed. São Paulo: Saraiva, 2010.

FAGUNDES, M. Seabra. Da desapropriação no direito constitucional brasileiro. Revista de Direito Administrativo, [S.1.], v. 14, p. 1-22, jan. 1948. ISSN 2238-5177. Disponível em: <http://bibliotecadigital.fgv.br/ojs/index.php/rda/article/view/10786/9775>. Acesso em: 21 Jun. 2015.

FALCONI, Luiz Carlos e HECK, José Nicolau A depredação das áreas de preservação permanente e de reserva legal florestal do bioma Cerrado como causa de desapropriação da propriedade rural por interesse social. Revista de Informação Legislativa. Brasília a. 42 n. 168 out./dez. 2005, p. 75-100.

FERREIRA, Lúcia Penna Franco. Reassentamentos dos atingidos por barragens: limites da competência regulatória da ANEEL. Revista Fórum de Direito Urbano e Ambiental. Belo Horizonte, ano 8, n. 46, jul. 2009.

FIUZA, César. Direito Civil: Curso Completo. 14ª ed. Belo Horizonte: Del Rey, 2010.

GOMES, Orlando. Direitos Reais. 19ª ed. São Paulo: Forense, 2004.

GRAU, Eros Roberto. A ordem econômica na Constituição Federal de 1988. 13. ed. São Paulo: Malheiros, 2008.

HIRONAKA, Giselda Maria Fernandes Novaes. Atividade agrária e proteção ambiental: simbiose possível. São Paulo: Cultural Paulista, 1997. 
LÔBO, Paulo Luiz Netto. Dos Contratos em Geral. In: PEREIRA, Rodrigo da Cunha (org.) Código Civil Anotado. Porto Alegre: Síntese, 2004.

LOUREIRO, Francisco Eduardo. Código Civil Comentado: doutrina e jurisprudência. $4^{\mathrm{a}}$ ed. Barueri, SP: Manole, 2010.

MAGRINI, Alessandra. A Avaliação de Impactos Ambientais. In: Margulis, S.. Meio ambiente. Aspectos técnicos e econômicos. Brasília: IPEA/PNUD, 1990.

MARÉS, Carlos Frederico. A Função Social da Terra. Porto Alegre: Sergio Antonio Fabris Editor, 2003.

MARÉS, Carlos Frederico. Desapropriação sanção por descumprimento da função social? Revista de Direito Agrário / Instituto Nacional de Colonização e Reforma Agrária. Ano 19, n ${ }^{\circ}$ 18. 2006.

MARQUESI, Roberto Wagner. Direito reais agrários e função social. 2 Ed., Curitiba: Juruá, 2011.

MEIRELLES, Hely Lopes. Direito Administrativo Brasileiro. 22. ed. São Paulo: Malheiros, 1997.

MELLO, Celso Antônio Bandeira de. Apontamentos sobre o poder de polícia. Revista de Direito Público $n^{\circ} 9$.

MORAES, Maria Celina Bodin de. A Caminho de um Direito Civil Constitucional. In: Revista de Direito Civil, $n^{\circ} .65$ (1993).

MOREIRA, YARA (org.). Vocabulário Básico de Meio Ambiente. FEEMA. Rio de Janeiro, 1990.

OLIVEIRA, Antônio Inagê de Assis. Introdução à legislação ambiental brasileira e licenciamento ambiental. Rio de Janeiro: Lumen Júris. 2005.

PARECER CONJUNTO/CPALNP-CGAPJP/CJ/MDA/N ${ }^{\circ} \quad 011 / 2004 \quad$ (VAF/JMPJ).

Desapropriação para fins de reforma agrária produtividade obtida mediante infração ou abuso fundamento nos incisos II, III e IV do art. 186 da CF/88. Disponível em: <http://www.oit.org.br/sites/all/forced_labour/legis_jur/temasdiversos/

PARECER\%20AMBIENTAL-REVISTO-31122004-011-2004-CPALNP-CGAPJP-CO.pdf>. Acesso em 30/11/2014.

PROENÇA, Alencar M. Direito Agrário. Porto Alegre: Síntese, 1999. 
REIS, L. F. S. S. D.; QUEIROZ, S. M. P. Gestão Ambiental em Pequenas e Médias Empresas. Rio de Janeiro, Qualitymark Ed., 2002.

REZEK, Gustavo Elias Kallás. Imóvel agrário: agrariedade, ruralidade e rusticidade. Curitiba: Juruá, 2007.

RODRIGUES, Sílvio. Direito civil - Direito das coisas. 26ª ed. São Paulo: Saraiva, 2001.

SANTOS, Boaventura de Sousa. O Estado e o direito na transição pós-moderna: para um novo senso comum. Coimbra-PT: Revista Crítica de Ciências Sociais, N.30, 1990.

SANTOS, João Paulo de Faria. Reforma Agrária e Preço Justo: A Indenização na Desapropriação para fins de reforma agrária e possibilidades de ruptura do individualismo proprietário. Brasília, 2008. Dissertação (Mestrado) - Faculdade de Direito, Universidade de Brasília.

SILVA, José Afonso da. Comentário Contextual à Constituição. 3a. Edição. São Paulo: Malheiros, 2007, p. 747.

SODERO, Fernando Pereira; Direito Agrário e Reforma Agrária, Livraria Legislação Brasileira Ltda., São Paulo, 1968.

TEPEDINO, Gustavo. Contornos Constitucionais da Propriedade Privada. In: Temas de Direito Civil. Rio de Janeiro: Renovar, 2004.

VENOSA, Sílvio de Salvo. Direitos reais. São Paulo: Atlas, 2001.

VIVANCO, Antônio Carlos. Teoría de Derecho Agrario, La Plata: Ediciones Librería Jurídicas, 1967. 